Research Article

\title{
Triaxial Permeability Experimental Study on Deformation and Failure Processes of Single-Fractured Rock Specimens
}

\author{
Taoli Xiao $\mathbb{D}^{1},{ }^{1}$ Mei Huang, ${ }^{1}$ and Min Gao $\mathbb{D}^{2,3}$ \\ ${ }^{1}$ School of Urban Construction, Yangtze University, Jingzhou, Hubei 434023, China \\ ${ }^{2}$ School of Civil Engineering, Dalian University of Technology, Dalian 116024, China \\ ${ }^{3}$ School of Civil Engineering and Architecture, Anhui University of Science and Technology, Huainan, Anhui 232001, China \\ Correspondence should be addressed to Taoli Xiao; 200536@yangtzeu.edu.cn and Min Gao; gmyxq0904@mail.dlut.edu.cn
}

Received 5 December 2019; Revised 24 May 2020; Accepted 15 June 2020; Published 16 July 2020

Academic Editor: Chao Tao

Copyright (C) 2020 Taoli Xiao et al. This is an open access article distributed under the Creative Commons Attribution License, which permits unrestricted use, distribution, and reproduction in any medium, provided the original work is properly cited.

A series of rock-like specimens with specific sizes and fracture inclinations was created in the laboratory. The different effects of seepage pressure on the deformation and failure characteristics between a conventional triaxial compression test and a triaxial permeability test were studied using a servo-controlled testing machine. Furthermore, the change in the permeability of singlefractured specimens was explored based on a triaxial permeability test. The results were as follows. Compared with those observed in the conventional triaxial compression test, the peak stress and corresponding axial strain decrease under seepage pressure in the triaxial permeability test, while the deformation modulus increased. With the increase of fracture length, the peak stress of specimen decreases due to the seepage pressure and the specimen showed tensile failure horizontally. The failure mode of the single-fractured specimens was changed by the seepage pressure. A closed relationship was observed between the failure modes and the permeability-stress curves. A shear failure along the crack surface will occur when the permeability abruptly changed later than the peak stress point. The dramatic change in the permeability indicated that the permeability channel was extended or new seepage paths were created. These conclusions can provide a valuable theoretical reference for the numerical simulation of excavation and design in stability analysis of jointed rock masses.

\section{Introduction}

Fractured rock masses, an example of the most complex types of rock masses, are often encountered in underground rock engineering-related situations, such as mining, water conservation, hydropower, and oil and gas field exploitation. In the process of geological history, many cracks, joints, faults, and other structural planes have formed in rock masses, the mechanical properties of which are poor. The effects of the structural surface should be considered in fractured rock masses, along with underground water movement $[1,2]$, because structural surfaces are the main channels for underground water. When the stress in a rock mass varies, the stress-seepage coupling effect in rock masses will reach a complex state. Permeability and deformation are the factors associated with the unstable failure of rock under the action of stress-seepage coupling [3]. Therefore, it is important to study the permeability characteristics of a rock mass, which is of vital significance for geological disaster prevention, safety evaluations in rock engineering, and research on hydromechanical coupling.

Currently, the servo-controlled testing machines can be used to effectively investigate the permeability characteristics of a rock mass. Although many relevant results are provided in the literature, the main rock mass was focused on granite [4,5], sandstone [6-9], limestone [10,11], and other complete specimens. However, irregular fractures are commonly seen in underground water-bearing rock engineering. These water-bearing fractures are defined as opentype cracks [12] because there is a certain width and there is no contact between the upper and lower surfaces of the fractures. Although seepage theory had been studied, investigations regarding seepage in a fractured rock mass are limited. 
Wang and $\mathrm{Xu}$ investigated the permeability evolution of limestone and sandstone with axial, lateral, and volumetric strain [13]. They proposed a conceptual model for the evolution of permeability with the strain and fitted the permeability-strain equation in the process of rock deformation and failure. Siavash et al. experimentally studied the effective stress law associated with the permeability of a limestone by performing constant-head permeability tests in a triaxial cell with different confining pressure and pore pressure conditions [14]. Jobmann et al. researched the permeability and effective porosity properties of fissured Opalinus clay via a triaxial test under increasing and decreasing confining pressure [15]. Suzanne et al. presented an experimental study of the relationship between the permeability of clayey rocks and their deformation at the macro- and microscales and found that permeability did not vary significantly at the sample scale [16]. Jiang et al. investigated the anisotropic damage and permeability variation in brittle rocks via triaxial compression tests with permeability measurements and found that the permeability significantly increased with the growth and coalescence of microcracks [17]. Badrul Alam et al. clarified the effect of the confining pressure on the permeability behaviors of various types of rock under triaxial compression, and the permeability of the rocks was measured at a confining pressure of 1-15 MPa. Then, a new equation representing permeability as a function of the confining pressure was proposed [18]. Chen et al. measured the permeability of core granite samples via triaxial tests and presented an empirical upper bound permeability model by relating the mechanisms involved in the microstructure alteration to the permeability change [19]. $\mathrm{Xu}$ and Yang measured the permeability of sandstone under increasing deviatoric stress under both short-term and creep compression conditions using the pulse transient technique and found that the variation patterns of permeability under different confining pressures were similar [20]. Wong et al. performed three different types of permeability tests of 23 intact and singly jointed rock specimens and evaluated intact metasandstone under a confining pressure up to $30 \mathrm{MPa}$ via the transient pulse water flow method [21]. Zou et al. studied the impact of stress on fracture deformation and the permeability of fractured rocks using laboratory tests [22]. Ma et al. studied the seepage properties of fractured rocks under different confining pressures and obtained the relationship between seepage properties and variations in the confining pressure [23]. Liu et al. investigated the evolution of granite gneiss during triaxial creep tests and defined the initial permeability, steady permeability, and peak permeability at various stress levels based on the test results [24]. Han et al. presented an experimental investigation of the mechanical behavior and permeability evolution of a typical porous limestone, the Anstrude limestone, and investigated the effects of the stress state on the permeability evolution in the axial direction of the sample [25].

The following conclusions can be drawn from the research results of the seepage properties of rock specimens: (1) many studies focus on the permeability coefficient or the relationship between the permeability and stress, and investigators attempt to obtain the relationship between the permeability and stress or strain through curving fitting. However, the fitting equations based on experimental results always vary because the lithologies of specimens are different; thus, a consistent law cannot be achieved. (2) Most experiments are focused on sandstone or siltstone with relatively high hydraulic permeability or specimens with penetrative seepage channels created by artificial cutting. However, few systematic seepage experiments of arbitrary fractured rock specimens have been performed, and the seepage research combining different fracture distributions, parameters, and specific confining pressures has not been reported. (3) A lack of systematic research exists regarding the strength properties and failure characteristics of fractured rock specimens under the coupled action of stress and seepage. The brittleness increases and the ductility decreases when a rock is softened by water; thus, the failure mode of a specimen should be changed. Related results have not been published in the existing literature.

Based on these issues, the seepage tests of a singlefractured rock specimen can be conducted, which are not only meeting the demands of investigating the fracture characteristics in deep underground engineering but also can provide abundant basic data associated with the multifield coupling of the fractured rock mass. Based on the conventional triaxial compression tests using an MTS815.03 electrohydraulic rock servo machine, single-fractured rock specimens with the same confining pressure and fracture conditions are designed at a reasonable osmotic pressure for seepage tests. The strength, deformation, and failure characteristics of single-fractured specimens under seepage conditions are analyzed, and the relationship between permeability and failure deformation of specimens is discussed.

\section{Physical Experiments}

2.1. Rock Specimens Manufacturing. Based on the investigation on the mechanical properties of the original marble rocks [26-29] and the similarity theory, the rock specimens are made of the composite material including the high silicon powder and mortar. The centroid of the preexisting fracture coincides with that of the fractured specimen, and the inclination of preexisting fracture is calculated counterclockwise from horizontal line to the fracture. The thickness of the single fracture is $0.2 \mathrm{~mm}$, made by the high strength and thin steel sheet. According to the mix ratio test, the mass ratio of the composite material is that $425 \#$ ordinary Portland cement: silica fume:quartz sand:iron powder:super plasticizer: water equals $1: 0.13: 0.8: 0.25$ : $0.02: 0.325$. The mixture slurry made by the composite materials according to the mass ratio was stirred for about 5 10 minutes in the homogenizer; then, the mixture slurry was poured into the prefixed mould on the vibratory table and vibrated for about 2 minutes at a proper frequency until the foam in the mortar overflowed. After that, the fixed thin steel sheet can be pulled out before the initial setting of the mortar. The model materials were allowed to stand for $24 \mathrm{~h}$, and then they were transferred to a dedicated pool for curing 
about 28 days. Then, form stripping and sampling were performed. The standard size of the specimens was $50 \mathrm{~mm} \times$ $100 \mathrm{~mm}$ (Figure 1). The mechanical properties of the intact rock specimen with no preexisting fracture were tested, and the mechanical properties were compared with those of the original intact marble rock shown in Table 1.

According to the similarity theory, not only the physical properties of the model specimens but also the mechanical properties should be similar to the original intact rock. The similarity constants in equation (1) are commonly used to measure their similarities:

$$
\left.\begin{array}{l}
C_{\sigma}=C_{\gamma} C_{l} \\
C_{\mu}=C_{\varepsilon}=C_{f}=1 \\
C_{\sigma}=C_{E}=C_{c}=C_{p t}=C_{R C} \\
C_{\delta}=C_{l}
\end{array}\right\} .
$$

Table 2 shows the similarity constants calculated by equation (1), which satisfy that

$$
\left.\begin{array}{l}
C_{\gamma} \approx C_{\mu} \approx C_{\phi}=1 \\
C_{E} \approx C_{R C} \approx C_{p t} \approx C_{c}
\end{array}\right\},
$$

where $C_{\sigma}, C_{\gamma}, C_{l}, C_{\mu}, C_{\varepsilon}, C_{f}, C_{E}, C_{c}, C_{\phi}, C_{p t}, C_{R C}$, and $C_{\delta}$ are stress, weight, geometry, Poisson's ratio, strain, frictional strength, elastic modulus, cohesion, internal frictional angle, tension strength, compression strength, and deformation similarity constant, respectively.

Figures 2(a) and 2(b) are stress-strain curves of rock-like material and marble specimen, respectively; the similarity of them are as follows: (1) both curves can be divided as four stages: the closure of original pores, elastic deformation and stable propagation of crack, unstable propagation and coalescence of the crack, and final failure; (2) the abrupt decline of stress after peak strength is a brittle characteristic.

Consequently, it can be concluded that (1) the similarity constants satisfy the equations based on similarity theory; (2) the rock-like material is similar to the real marble specimen in aspects including mechanical and physical characteristics, and the high strength silica powder material has a relatively stable property, which guarantees that it is unaffected by the external circumstances; it also has an advantage of being easily available. For the above reasons, rock-like material can substitute the real marble rock to be subjected to experiment.

2.2. Experimental Design. The experiments were conducted by using the MTS815.03 electrohydraulic servo-controlled test system at Shandong University of Science and Technology, China. The system provides loading and displays external pressures during the test. The experimental design is shown in Figure 3, which illustrates the system and its principle. The porous plates are attached to the upper and lower ends of the specimen during the test. The porous plates ensure that the fluid flows evenly, and a felt filtration pad prevents the system from being polluted by the fluid. The rock specimen and the cylinder tube are separated by an epoxy resin layer, which can prevent the radial flow of the fluid. Additionally, to change the water flow channel, a small hole is drilled in the center of the upper and lower porous plates.

The transient method is used to measure the permeability of the MTS testing machine. The basic principles are as follows. According to the experimental requirements, the pressure applied during the experiment should be designed initially. When the experiment begins, the axial pressure $P_{1}$, the confining pressure $\mathrm{P}_{2}$, and the pore pressure $\mathrm{P}_{3}$ are firstly applied, and $\mathrm{P}_{3}<\mathrm{P}_{2}$ is maintained throughout the experiment. Then, the water pressure $\mathrm{P}_{4}$ at the lower end of the specimen is decreased (at the beginning, $\mathrm{P}_{4}=\mathrm{P}_{3}$ ). After that, a seepage pressure difference $\Delta \mathrm{P}$ is formed at both ends of the specimen (the maximum seepage pressure difference $\Delta \mathrm{P}$ of the equipment is less than $2 \mathrm{MPa}$, and $\Delta \mathrm{P}$ is generally equal to $1.5 \mathrm{MPa}$ in permeability experiments), which causes the water to flow through the specimen. During the seepage process, $\Delta \mathrm{P}$ decreases continuously, and the decreased rate is related to the type and structure of the rock mass, the height of the specimen (seepage path), the cross-sectional size of the specimen, the viscosity and density of the fluid, and the stress state and stress level. According to the data collected automatically by the computer during the test, the rock permeability calculation formula can be expressed as follows:

$$
k=\frac{1}{5 n} \sum_{i=1}^{n} 526 \times 10^{-6} \times \lg \left[\frac{\Delta \mathrm{p}(i-1)}{\Delta \mathrm{p}(i)}\right],
$$

where $n$ is the number of the date acquisition lines, $\Delta \mathrm{p}(i-1)$ is the seepage pressure difference of the $(i-1)$ th line, and $\Delta \mathrm{p}(i)$ is the seepage pressure difference of the $i$ th line.

The presence of structural faces in a rock or rock masses will degrade the strength characteristics of the rock. In addition, the mechanical properties of rock masses will be affected when fissures are filled with water. In this paper, based on the conventional triaxial loading test of the singlefracture rock specimens [1,26-28], a representative part of the samples is selected to study the seepage loading properties under a confining pressure. Before the seepage test, all the selected samples were immersed in pure water at room temperature for 3 months to fully saturate the samples. In multiple tests, the loading rate of axial loader $\mathrm{P} 1$ is $0.5 \mathrm{KN} / \mathrm{S}$; the confining pressure and water pressure were set to $\mathrm{P}_{2}=14 \mathrm{MPa}, \mathrm{P}_{3}=12 \mathrm{MPa}$, and $\mathrm{P}_{4}=10.5 \mathrm{MPa}$ throughout the tests. Thus, the seepage pressure difference between the two ends was $\Delta \mathrm{p}=1.5 \mathrm{MPa}$. The design of the tests is shown in Table 3.

\section{Test Results and Analysis}

3.1. Characteristics of the Strength and Deformation. The strength and deformation indices of the specimens, as shown in Table 4, were calculated using the results of the seepage loading and conventional triaxial compression tests under the same confining pressures of $\sigma_{3}=14 \mathrm{MPa}$ and $\Delta \mathrm{P}=1.5 \mathrm{MPa}$. The relevant data from the two test types in Table 4 were analyzed, and the following findings were concluded: (1) During seepage loading, the peak stress and axial strain of each sample decreased compared with those in 


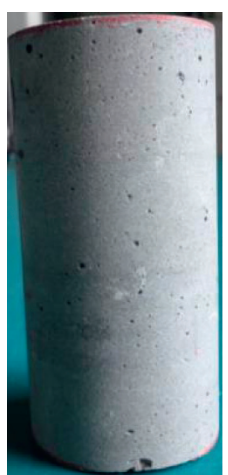

Series of W1

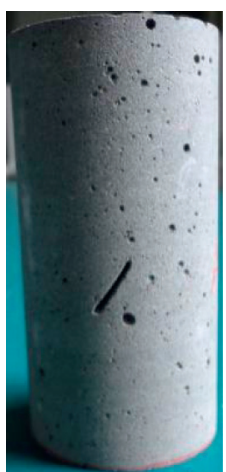

Series of A2

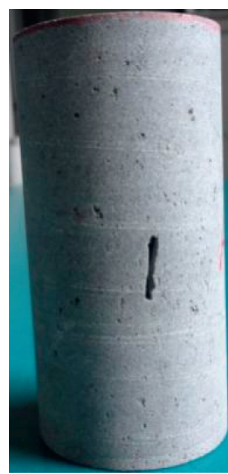

Series of $\mathrm{A} 3$

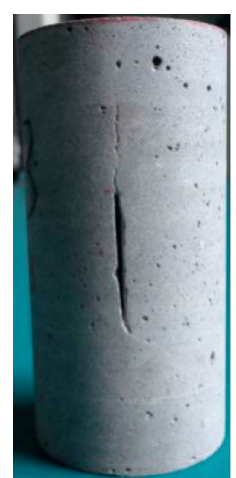

Series of B3

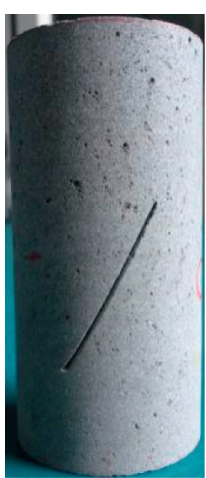

Series of C2

FIGURE 1: Intact specimen and single-fractured specimen.

TABle 1: Physicomechanical properties of the specimen and prototype.

\begin{tabular}{lccccccc}
\hline Materials & $\begin{array}{c}\text { Density } \\
\left(\mathrm{g} / \mathrm{cm}^{3}\right)\end{array}$ & $\begin{array}{c}\text { Elastic modulus } \\
(\mathrm{GPa})\end{array}$ & $\begin{array}{c}\text { Poisson's } \\
\text { ratio }\end{array}$ & $\begin{array}{c}\text { Compression strength } \\
(\mathrm{MPa})\end{array}$ & $\begin{array}{c}\text { Tension strength } \\
(\mathrm{MPa})\end{array}$ & $\begin{array}{c}\text { Cohesion } \\
(\mathrm{MPa})\end{array}$ & $\begin{array}{c}\text { Fraction angle } \\
\left({ }^{\circ}\right)\end{array}$ \\
\hline Specimen & 2.21 & 14.19 & 0.12 & 70.12 & 2.16 & 20.73 & 35.00 \\
Prototype & 2.70 & 25.20 & 0.14 & 199.20 & 5.57 & 61.13 \\
\hline
\end{tabular}

TABLE 2: Similarity constant about physicomechanical parameters between prototype rock and model specimen.

\begin{tabular}{lccccccc}
\hline Similarity constants & $C_{\gamma}$ & $C_{E}$ & $C_{\mu}$ & $C_{R C}$ & $C_{p t}$ & $C_{c}$ & $C_{\phi}$ \\
\hline Prototype/specimen & 1.22 & 1.78 & 1.17 & 2.84 & 2.58 & 2.95 & 1.02 \\
\hline
\end{tabular}

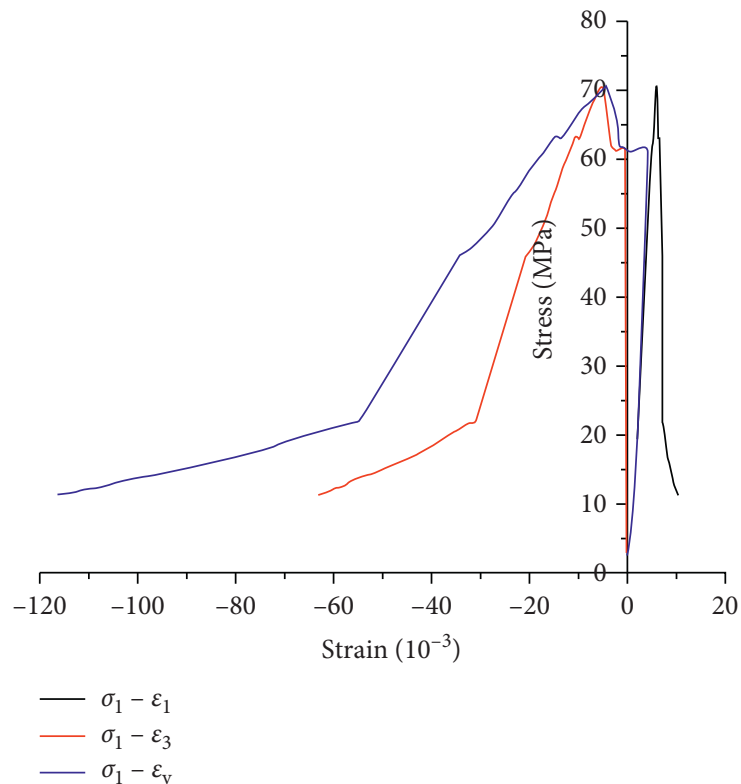

(a)

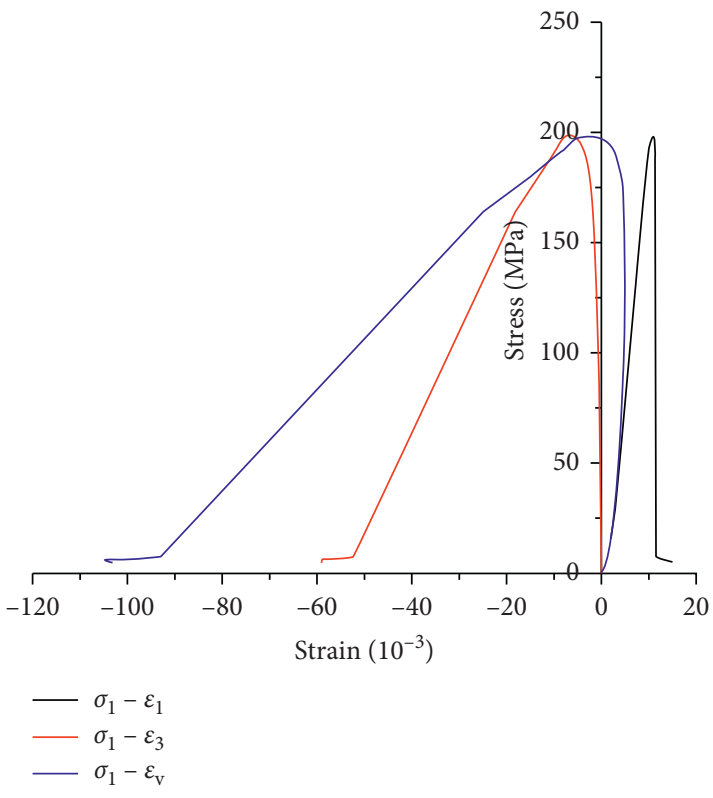

(b)

Figure 2: The stress-strain curves of rock-like specimen and marble specimen. (a) Rock-like specimen. (b) Marble specimen.

conventional triaxial loading test because of the effect of the seepage pressure, while the deformation modulus increased, which indicated that the seepage pressure decreased the rock mass strength. (2) For a single-fractured specimen, the horizontal strain changed from a compressive strain (positive) in the traditional triaxial loading test to a tensile strain 


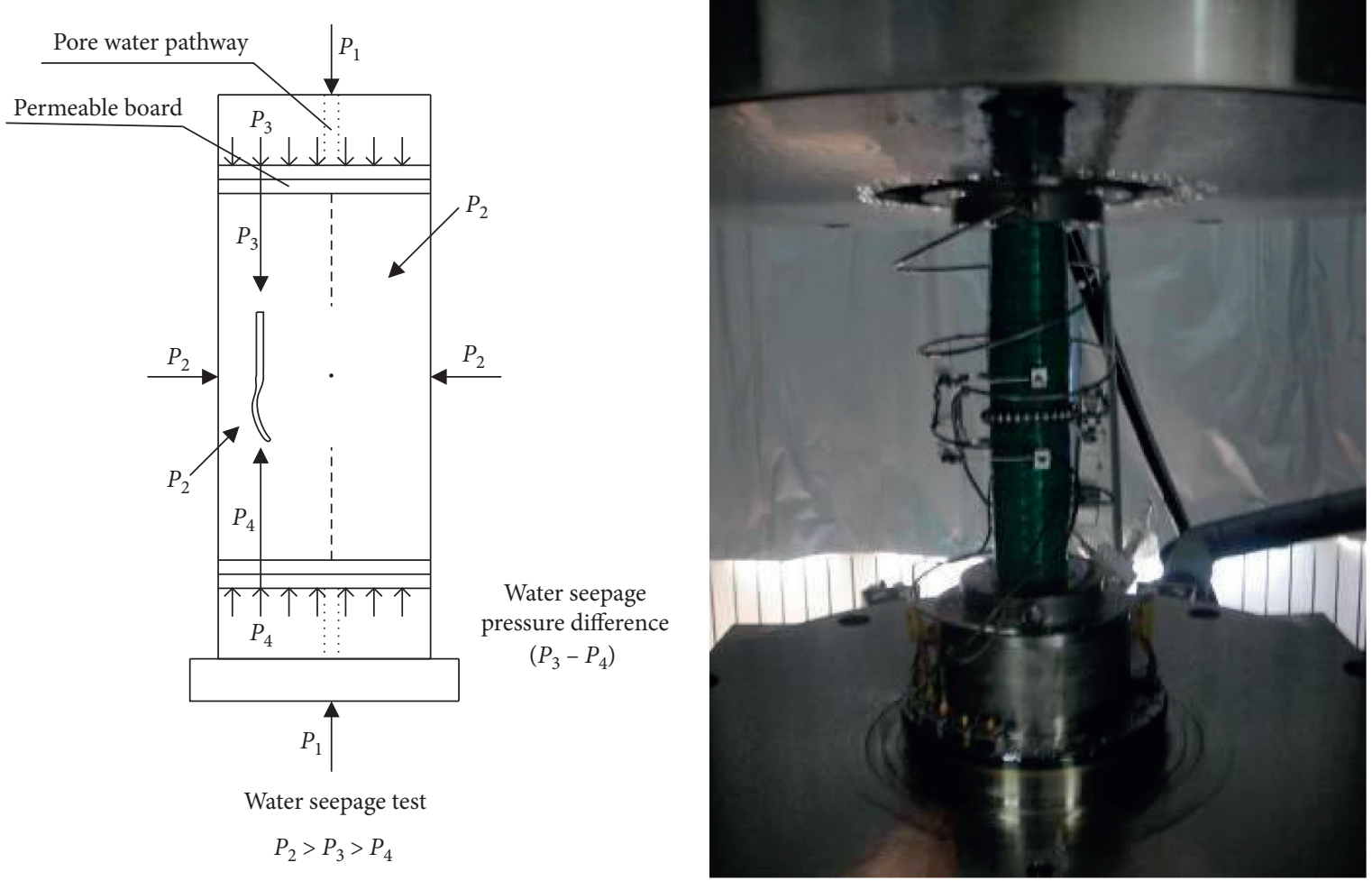

FIGURE 3: The principle of the penetration test.

TABLE 3: The design of physical tests.

\begin{tabular}{|c|c|c|c|}
\hline Specimen no. & Fracture angle $\left(^{\circ}\right)$ & Fracture length $(\mathrm{mm})$ & Test type \\
\hline W1-2 & Intact rock & Intact rock & Triaxial loading test \\
\hline W1-1 & Intact rock & Intact rock & Triaxial seepage test \\
\hline A2-1 & 60 & 13 & Triaxial loading test \\
\hline A2-2 & 60 & 13 & Triaxial seepage test \\
\hline A3-3 & 88 & 13 & Triaxial loading test \\
\hline A3-2 & 88 & 13 & Triaxial seepage test \\
\hline B3-2 & 88 & 26 & Triaxial loading test \\
\hline B3-1 & 88 & 26 & Triaxial seepage test \\
\hline $\mathrm{C} 2-1$ & 60 & 39 & Triaxial loading test \\
\hline $\mathrm{C} 2-5$ & 60 & 39 & Triaxial seepage test \\
\hline
\end{tabular}

TABLE 4: The characteristics of the strength and deformation of the test results.

\begin{tabular}{|c|c|c|c|c|c|c|c|c|}
\hline \multirow{2}{*}{ Specimen no. } & \multirow{2}{*}{$\begin{array}{c}\text { Max stress } \\
\sigma_{1}-\sigma_{3}(\mathrm{MPa})\end{array}$} & \multicolumn{2}{|c|}{ Strain } & \multirow{2}{*}{$\begin{array}{c}\text { Deformation modulus } \\
\mathrm{E}_{50}(\mathrm{GPa})\end{array}$} & \multicolumn{4}{|c|}{$($ Seepage-triaxial) $/$ triaxial $\times 100 \%$} \\
\hline & & $\varepsilon_{1}$ & $\varepsilon_{3}$ & & Max stress & Axial strain & Lateral strain & Deformation modulus \\
\hline W1-2 & 131.867 & 0.0119 & 0.0057 & 12.877 & & -420 & -54 & 985 \\
\hline W1-1 & 128.232 & 0.0114 & 0.0026 & 14.145 & 2.76 & -4.20 & -54 & \\
\hline A2-1 & 85.864 & 0.0091 & 0.0012 & 8.586 & & & & \\
\hline A2-2 & 83.267 & 0.0080 & -0.0011 & 10.355 & 2 & & & 20.60 \\
\hline A3-3 & 98.615 & 0.0096 & 0.0008 & 9.456 & -345 & -2292 & -26250 & 5191 \\
\hline A3-2 & 95.212 & 0.0074 & -0.0013 & 14.365 & -3.45 & -22.92 & -262.50 & 51.91 \\
\hline B3-2 & 112.641 & 0.0101 & 0.0018 & 10.166 & & & & \\
\hline B3-1 & 102.025 & 0.0068 & -0.0008 & 15.853 & & & & 55.94 \\
\hline $\mathrm{C} 2-1$ & 68.086 & 0.0162 & -0.0022 & 4.014 & & & & \\
\hline $\mathrm{C} 2-5$ & 56.370 & 0.0060 & -0.0011 & 11.630 & -17.21 & & & 189.74 \\
\hline
\end{tabular}


(negative) in the seepage triaxial loading test. (3) The axial strain and deformation modulus were influenced by the fracture length and fracture inclination angle, and the overall trend was that the axial strain and deformation modulus increased as the fracture geometry values increased. (4) The influence of the fracture inclination angle on the peak stress variation was small; when the crack length was $13 \mathrm{~mm}$, the peak stress of the A2 series (inclination angle: $60^{\circ}$ ) was reduced by $3.02 \%$, and the peak stress of the A3 series (inclination angle: $90^{\circ}$ ) was reduced by $3.45 \%$. Thus, the amplitude was essentially the same. However, the length of the fracture determined the peak stress reduction; the peak stress decreased by $3.45 \%, 9.42 \%$, and $17.21 \%$, when the crack length was $13 \mathrm{~mm}$ (A3 series), $26 \mathrm{~mm}$ (B3 series), and $39 \mathrm{~mm}$ (C2 series), respectively.

The above experiments demonstrated that the seepage pressure exerted mechanical and erosion effect on the strength and deformation of specimen. As for mechanical aspect, the water contained in the fracture exerted hydraulic fracturing effect on fracture tip, which accelerates crack propagation, inducing more severe deformation of the specimen. At the same time, the water contained in fracture gradually invaded into the rock-like material; surrounding mineral particles constituted the specimen, leading to a lower gravity between the mineral particles and thus a weaker cementation between them and finally a lower strength of the specimen.

\subsection{Failure Characteristics of Single-Fractured Specimens.} The data in Table 4 showed that when the permeating water pressure was applied to a single-fractured specimen, the axial strain was reduced compared with that in the conventional triaxial test, but the transverse strain changed from compressive strain to tensile strain. Thus, we examined whether the failure mode of the specimen also changed due to the permeating water pressure. Failure modes of the macrofracture in the seepage loading and unloading tests and the conventional triaxial test are shown in Figure 4. The failure modes of the rock specimens of the two test types are analyzed, and the following results are obtained: (1) For the W1 series of the complete specimens of the two tests shown in Figure 4(a), the main rupture traces of the specimens in the two tests both exhibited shear failure, but the shear failure of specimen W1-2 was a fold line, while the shear failure surface of specimen W1-1 had a certain "thickness." Additionally, the specimen was broken violently in the range of this "thickness." (2) For the A2 series of the fracture specimens of the two tests shown in Figure 4(b), the macroscopic main rupture trace of specimen A2-1 exhibited " $X$ " shear failure in the conventional triaxial test, while the rupture trace of specimen A2-2 exhibited shear failure along the fracture inclination angle in the seepage loading test, and horizontal microcracks appeared in the middle of specimen A2-2. (3) For the A3 series of the fracture specimens of the two tests shown in Figure 4(c), the macroscopic main rupture trace of specimen A3-3 exhibited " $\mathrm{X}$ " shear failure in the conventional triaxial test, while the macroscopic main rupture trace of specimen A3-2 exhibited inclined plane shear failure in the seepage loading test, with the failure surface having a certain "thickness." Additionally the horizontal crack through specimen A3-2 was clearly extended in the middle of the prefabricated fracture. (4) For the B3 series of the fracture specimens of the two tests shown in Figure $4(\mathrm{~d})$, the macroscopic main rupture trace of specimen B3-2 exhibited " $X$ " shear failure in the conventional triaxial test, and many other rupture traces existed around the prefabricated fracture. The macroscopic main rupture trace of specimen B3-1 exhibited zigzag inclined plane shear failure in the seepage loading test and the circular-through cracks were irregularly extended at both ends of the prefabricated fracture. (5) For the $\mathrm{C} 2$ series of the fracture specimens of the two tests shown in Figure 4(e), the macroscopic main rupture trace of specimen C2-1 exhibited pure shear failure along the prefabricated fracture in the conventional triaxial test, while the failure of the seepage loading specimen was associated with antiwing crack damage [27]. The antiwing crack was an approximately horizontal crack at both ends of the prefabricated fracture.

In conclusion, the permeated water pressure did not change the failure mode of the completely saturated specimen, but it affected the expansion of the seepage channel in the shear failure surface. For a single-fracture specimen, hydromechanical coupling accelerated the crack tip expansion of the prefabricated fracture, increased the force on the prefabricated fracture surface, and initiated a new seepage channel. Additionally, the horizontal strain of the specimens changed from compressive strain to tensile strain; thus, the failure mode was fundamentally changed.

With the effective stress principle implemented, the experimental phenomenon is analyzed as follows: the effective stress will go down as the seepage pressure exists in the fractured specimen, and the deviator stress $\left(\sigma_{1}-\sigma_{3}\right)$ kept a constant value in the whole experiment process, which will reach ultimate strength more easily according to Mohr-Coulomb Principle; at the same time, the pore water exerted pressure expansion effect on the preexisting fracture, which accelerates crack propagation process. Consequently, the seepage pressure plays a role in reducing the value of the confining pressure, leading to an increase of brittleness and decrease of ductility, directly changing the failure pattern of fractured specimen.

\subsection{Seepage Characteristics of the Single-Fractured Specimens.} The permeability-deviatoric stress and permeability-axial strain-horizontal strain curves of each specimen during the seepage loading test are shown in Figures 5-14. These permeability curves showed the following results. The permeability curve of a single-fractured specimen could be summarized as follows: in the initial compaction stage, the original micropores in the internal structure of the specimen, which were perpendicular to the principal stress, were closed or compacted, and the permeability of the specimen decreased with increasing axial stress. In the stage of linear elastic deformation, as the axial stress increased, the permeability of the specimen exhibited a gradual increasing trend, but the range changed very slightly, which may reflect 


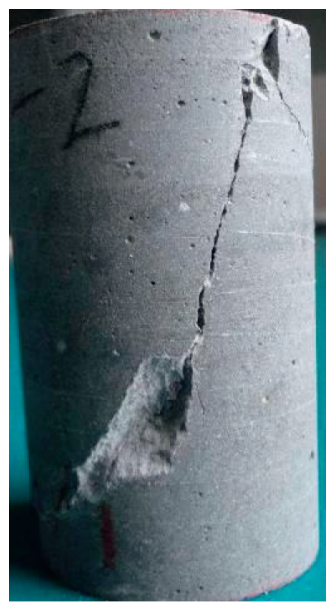

W1-2

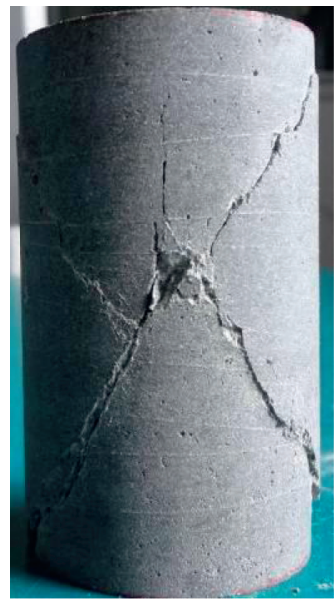

A3-3

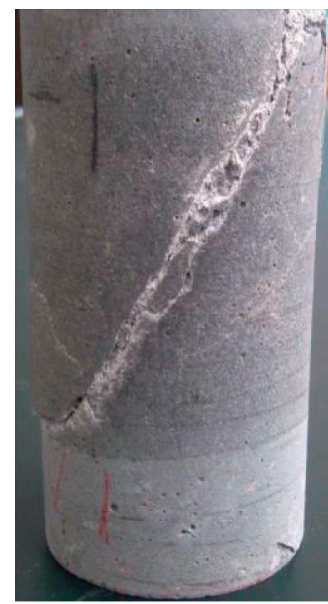

W1-1

(a)

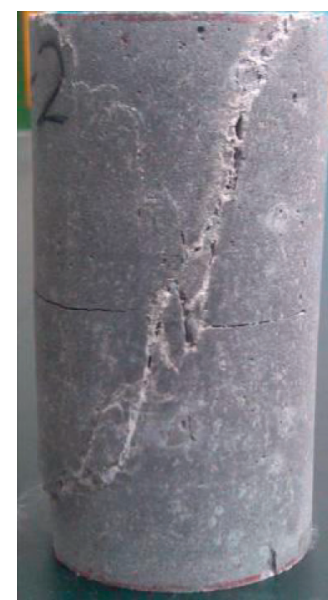

A3-2

(c)

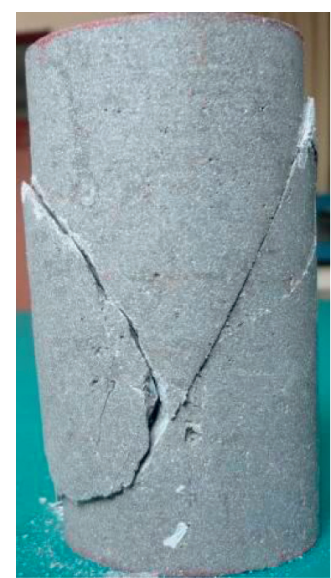

C2-1

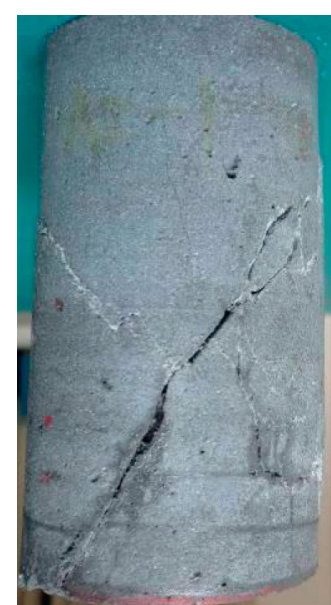

A2-1

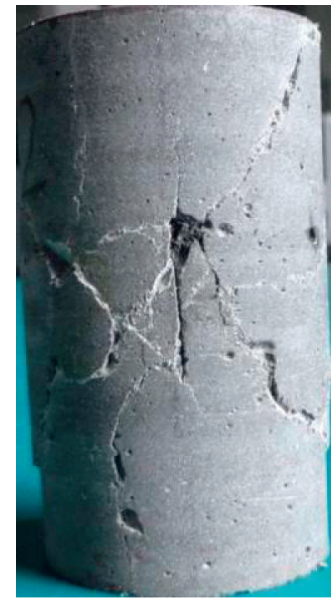

B3-2
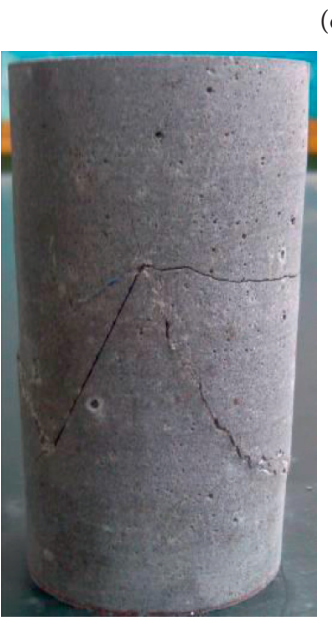

C2-5

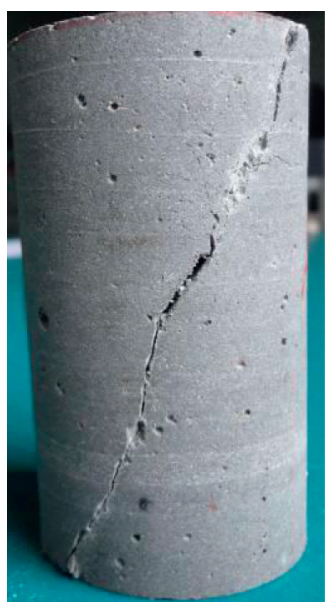

A2-2

(b)

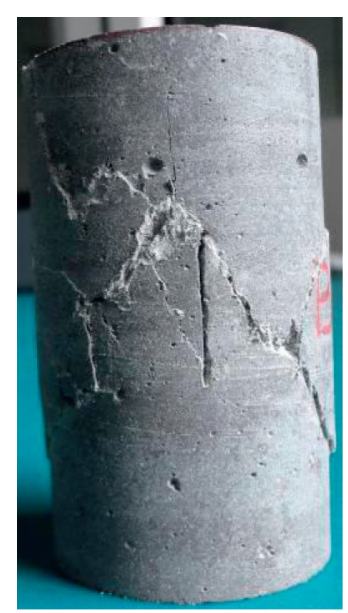

B3-1

(d)

(e)

FIgURE 4: Failure modes of single-fractured rock specimens under the two type tests. (a) Failure modes of W1-2 and W1-1. (b) Failure modes of A2-1 and A2-2. (c) Failure modes of A3-3 and A3-2. (d) Failure modes of B3-2 and B3-1. (e) Failure modes of C2-1 and C2-5. 
the permeability value. This phenomenon indicated that a microfracture was initiated and the original pore was expanded inside the specimen under the combined actions of the external load and pore pressure, which resulted in the corresponding changes in permeability. In the stage of elastoplastic deformation and peak strength, as the axial stress increased, the microcracks in the internal structure of the specimen gradually expanded into macroscopic cracks. Then, the specimen cracked and the permeability coefficient increased considerably. In the strain softening stage, the opening fracture of the cracked specimen recompacted and closed under the action of stress; thus, the permeability of the specimen decreased. As time passed, the cracked rock mass dislocated and exhibited a climbing effect along the rupture surface. Additionally, as the pore water pressure decreased, erosion and mechanical effects were generated; thus, the upper and lower ends of the macroscopic crack surface of the specimen broke. Then, the seepage channel widened and the axial and lateral strain increased. When the macrorupture zone formed with a certain thickness, the permeability increased sharply and reached a peak value.

The change in the permeability of seepage specimens W1-1, A2-2, A3-2, and C2-5 showed a close match with the change trend in the axial strain and horizontal strain. Additionally, as the axial stress increased, the permeability, axial strain, and horizontal strain gradually increased. Moreover, when the permeability increased sharply, the growth rate of the lateral strain and axial strain did not change considerably and kept the trend of early growth. Therefore, the seepage water pressure did not change the strain development trend of the specimen.

The permeability-axial strain-axial stress curves were analyzed, and the peak stress of specimens W1-1, A2-2, and A3-2 was observed before the permeability increased sharply. Additionally, the failure of the seepage specimens (Figures 4(a), 4(b), and 4(c)) was shear failure of singleinclined plane. In addition, when the peak stress of the specimens was observed after the permeability increased sharply, the failure of the seepage specimens was shear failure along the prefabricated fracture surface. The results showed that the change in permeability of single-fractured specimens was closely related to their failure mode. The phenomenon could be analyzed from the point of view of seepage and stress coupling. Under the actions of seepage pressure and stress, the component force paralleled to the fracture plane caused the crack tip to extend continuously until the specimen broke due to shear stress; then, the stress peak occurred. However, the force perpendicular to the fracture plane created a certain thickness range of localized specimen fragmentation at both ends of the prefabricated fracture until the broken belt formed along the shear failure surface; then, the seepage channel further expanded and the permeability increased sharply.

Figures 11 and 12 show that the peak stress and the maximum permeability value of specimen B3-1 appeared almost simultaneously, and when the peak stress gradually decreased, the permeability also gradually decreased. This phenomenon showed that the seepage channel did not expand further after the failure of the specimen, but it was

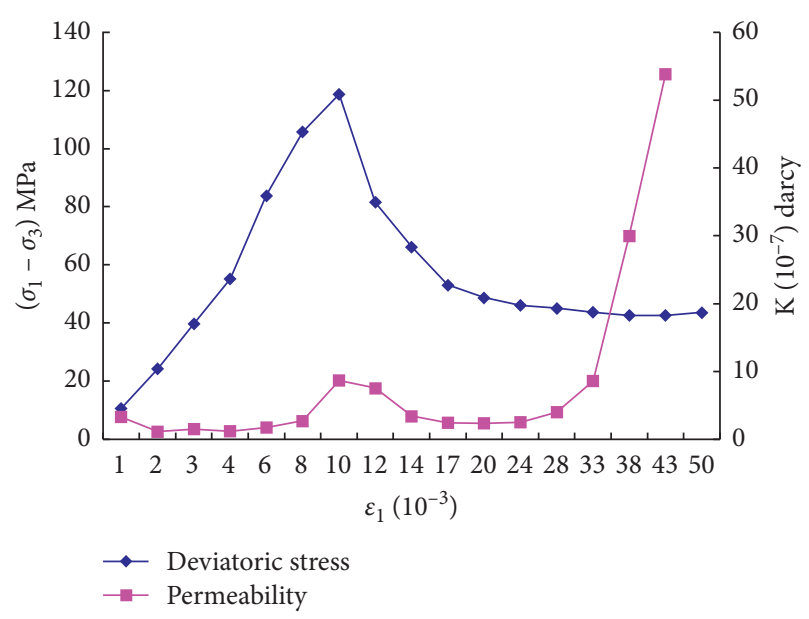

FIGURe 5: Permeability-principal stress difference curves of W1-1.

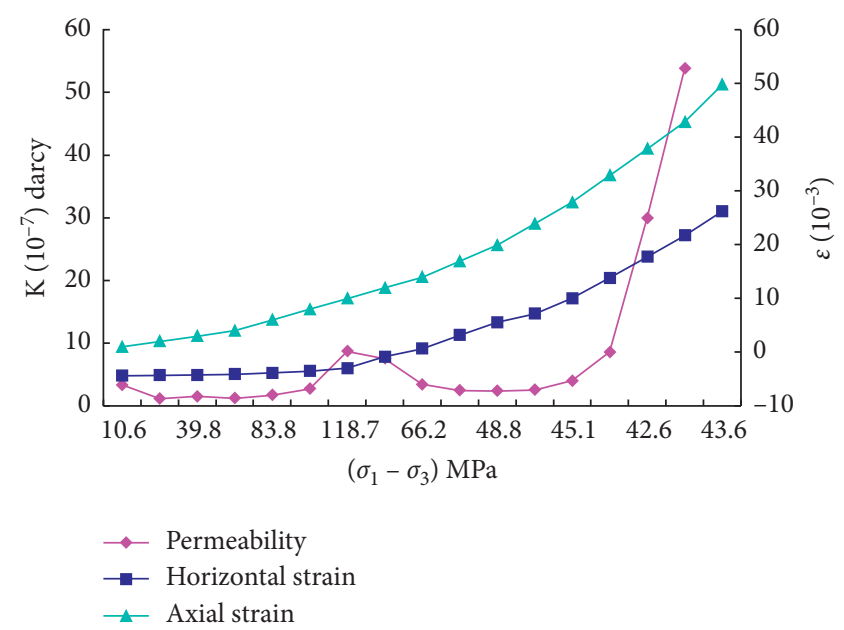

FIgURE 6: Permeability-horizontal strain-axial strain curves of W1-1.

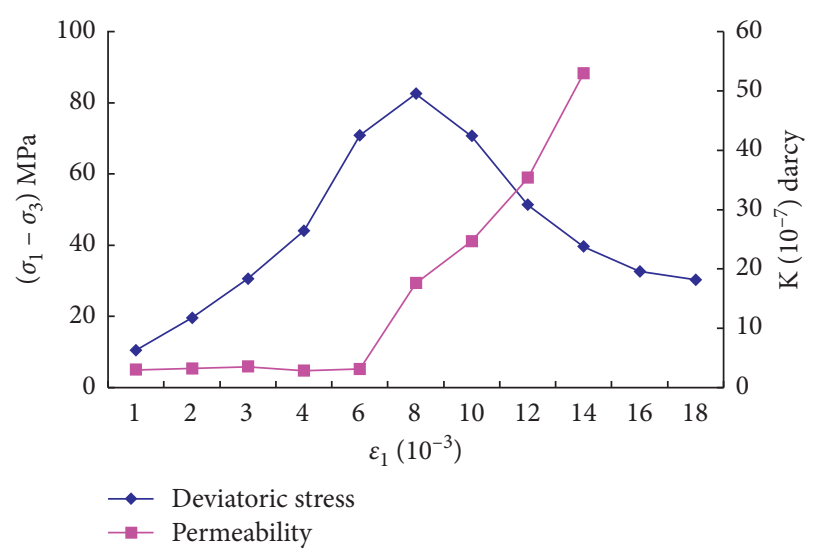

FIgURE 7: Permeability-principal stress difference curves of A2-2.

compressed stepwise. Under the coupling action of the seepage and stress, the specimen underwent shear failure combined with the failure shown in Figure 4(d). Then, the 


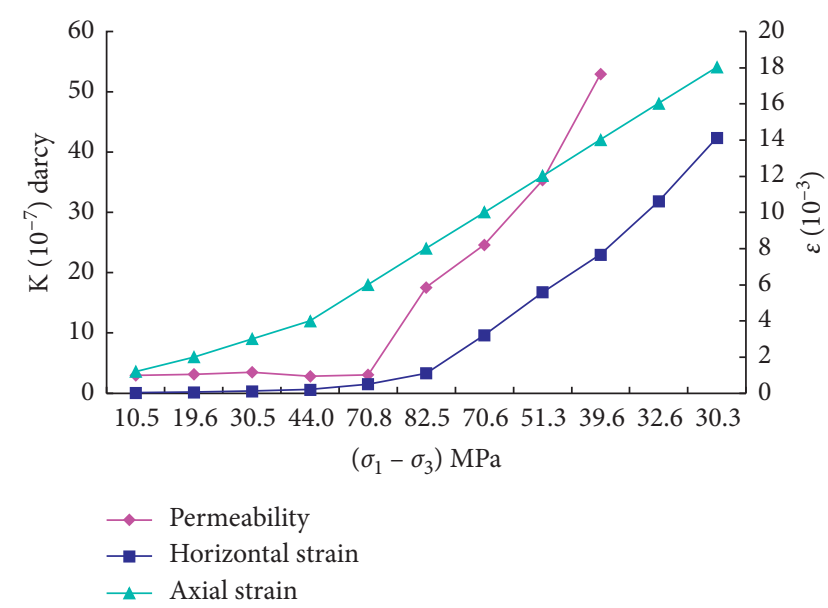

FIgURe 8: Permeability-horizontal strain-axial strain curves of A2-2.

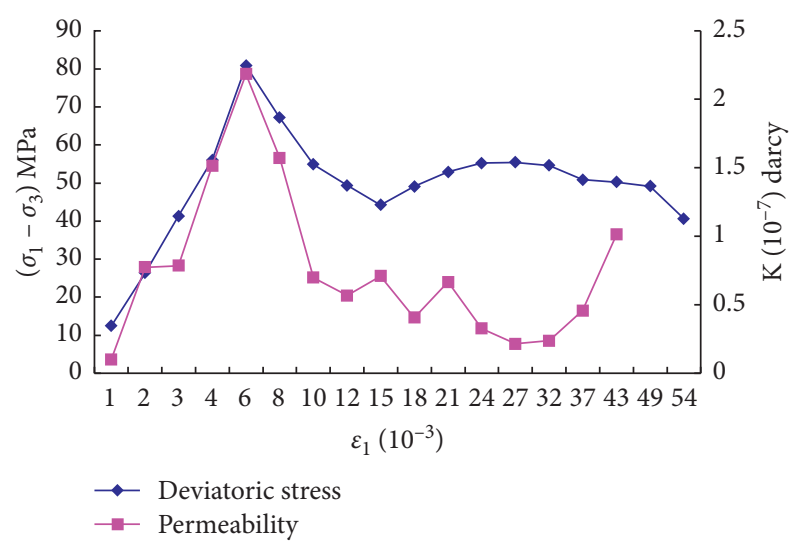

FIGURE 9: Permeability-principal stress difference curves of A3-2.

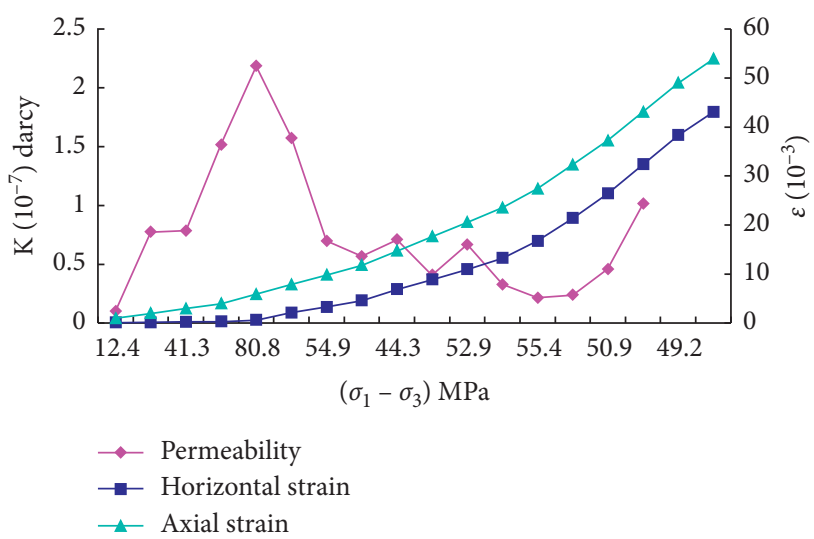

FIgURe 10: Permeability-horizontal strain-axial strain curves of A3-2.

compressive stress further narrowed the seepage channel after the specimen was damaged. Therefore, the stress and permeability of the specimen exhibited gradual decreasing trends.

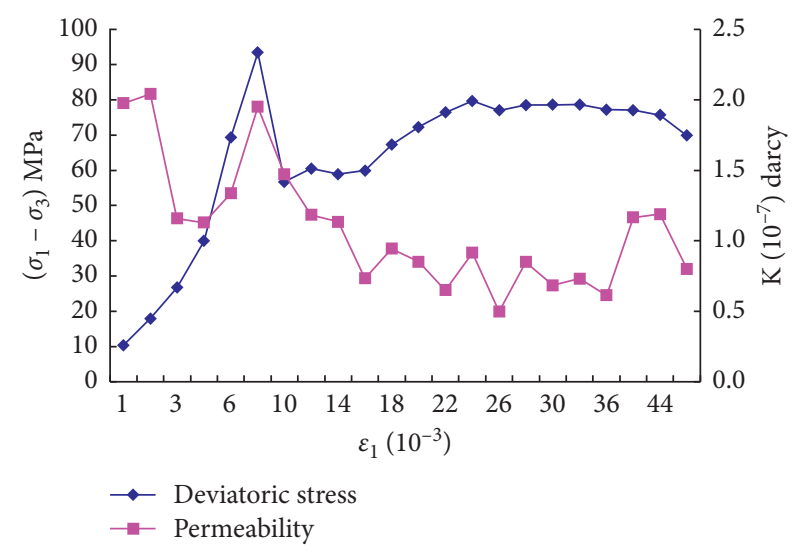

FIgURE 11: Permeability-principal stress difference curves of B3-1.

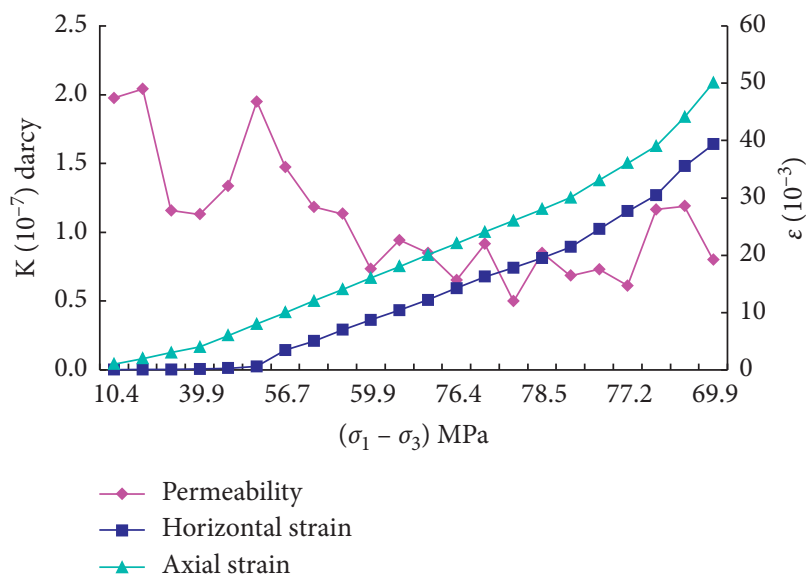

FIgURE 12: Permeability-horizontal strain-axial strain curves of B3-1.

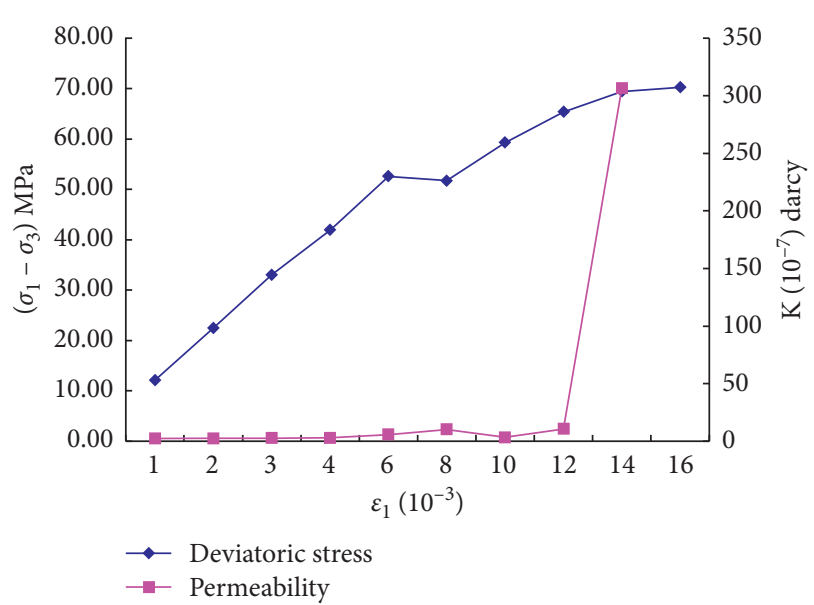

FIGURE 13: Permeability-principal stress difference curves of C2-5.

Figures 13 and 14 illustrate that the permeability of specimen C2-5 began to increase sharply, but its stress increased slowly. The analysis of Figure 4(e) suggested that the 


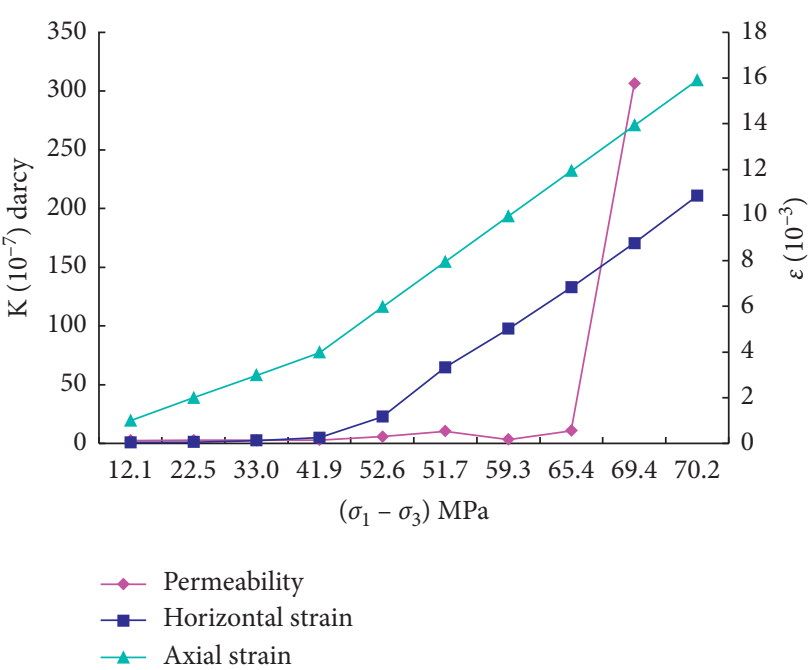

FIgURe 14: Permeability-horizontal strain-axial strain curves of C2-5.

failure mode of the specimen was antiwing crack damage, but shear failure did not form along the prefabricated fracture. New crack propagation was induced at the tip of the prefabricated fracture under the actions of the seepage water pressure and stress; therefore, the antiwing crack was generated. The permeability of the specimen increased sharply when the number of seepage channels increased.

In summary, the following conclusions can be obtained: (1) Due to the presence of a prefabricated fracture, the crack tip is more likely to expand along the fracture surface under the actions of the seepage pressure and stress. At the same time, the force perpendicular to the fracture plane will break a certain thickness of the rock surface, induce new cracks, or extend existing cracks. (2) The sharp increase in the permeability may occur before the peak stress (as observed for C2-5), with the peak stress (as observed for B3-1) simultaneously, or after the peak stress (as observed for W1-1, A22 , and A3-2). Overall, when the failure mode of the specimen is single inclined plane shear failure and the peak stress usually occur before the point when the permeability increases sharply. When the specimen is subjected to compression and undergoes shear failure, the peak stress occurs almost simultaneously with the sharp increase in the permeability. Additionally, peak stress occurs after the sharp increase of the permeability when the specimen is destroyed by an antiwing crack. (3) The permeability sharply increases when the seepage channel becomes thicker (the fracture surface transforms into a broken zone) or the number of seepage channels increases (more cracks). The thickening of the seepage channel confirms not only the process of erosion due to fissure water but also the occurrence of mechanical actions. The changes in the seepage channels further reveal the mechanical effects of the fissure water pressure.

\section{Conclusions}

In this paper, single-fractured specimens with specific inclinations and sizes of fractures were fabricated in a rock-like model material to perform an indoor triaxial seepage loading test under a confining pressure of $14 \mathrm{MPa}$. Through a comparative study with a conventional triaxial loading test, the following main conclusions were drawn:

(1) Due to the effect of the seepage water pressure, the strength and deformation characteristics of the specimen changed, the peak stress of the specimen decreased, the axial strain at the peak stress was reduced, and the deformation modulus increased. The crack length determines the magnitude of the peak stress degradation, and the crack angle and length determine the magnitudes of the changes in the axial strain and deformation modulus.

(2) In the case of the seepage loading test, the horizontal strain of the single-fractured specimen changed from compressive strain in the normal triaxial compression test to tensile strain.

(3) The failure mode of the complete specimen did not change, but the failure mode of the single-fractured specimen changed because of the effect of the seepage water pressure.

(4) During the seepage loading test, the failure mode of the single-fractured specimen was closely related to the seepage-stress curve. When the sharp increase in the permeability occurred after the peak stress point, the failure mode of the specimen was shear failure along the prefabricated fracture.

(5) In the seepage loading test, the sharp increase in permeability reflected the expansion of the seepage channel, the fragmentation of the specimen within a certain thickness along the sides of the shear plane, or the initiation of new seepage channels at the tip of the prefabricated fracture.

In this paper, only single-fractured specimens with a confining pressure of $14 \mathrm{MPa}$ were selected for analysis in the triaxial seepage loading test because the triaxial seepage loading test is a multichannel combination of equipment and systems. Additionally, the test operation is sophisticated; the success rate of specimens is low; the test cost is high; and the test provides a high acquisition ability for seepage data. However, the conclusions obtained can benefit future research. Based on this research, future studies can be performed from the following perspectives. First, the permeability characteristics can be studied under lower and higher confining pressures, with a focus on the relationship between the failure mode and confining pressure level. Second, the influence of fracture geometry (length, inclination, and number of cracks) on the strength and deformation characteristics of seepage specimens can be investigated. Third, the relationship between the permeability surge, crack expansion, and specimen damage can be studied via a seepage test combined with microscopic technique (e.g., computerized tomography or X-ray scanning).

\section{Data Availability}

The data used to support the findings of this study are available from the corresponding author upon request. 


\section{Conflicts of Interest}

The authors declare that they have no conflicts of interest.

\section{Acknowledgments}

This work was supported by the National Natural Science Foundation of China (Grant no. 51274157) and Jingzhou Science and Technology Plan Project, Hubei Province (Grant nos. 2019CC48 and 2019AC27).

\section{References}

[1] T. L. Xiao, X. P. Li, and Y. H. Guo, "Experimental study of failure characteristic of single jointed rock mass under triaxial compression tests," Rock and Soil Mechanics, vol. 33, no. 11, pp. 3251-3261, 2012, in Chinese.

[2] T. Jiang, X. Pan, J. Lei, J. Zhang, and W. Wang, "Rupture and crack propagation in artificial soft rock with preexisting fractures under uniaxial compression," Geotechnical and Geological Engineering, vol. 37, no. 3, pp. 1943-1956, 2018.

[3] W. M. Xiao, C. C. Xia, and R. G. Deng, "Advances in development of coupled stress-flow test system for rock joints," Chinese Journal of Rock Mechanics and Engineering, vol. 33, no. S2, pp. 3456-3465, 2014.

[4] M. D. Zoback and J. D. Byerlee, "The effect of micro crack militancy on the permeability of Westerly granite," Journal of Geophysical Research, vol. 80, pp. 752-755, 1997.

[5] W. Wang, Z. Zheng, R. B. Wang et al., "Experimental study of permeability properties of granitic gneiss under different stress paths," Chinese Journal of Rock Mechanics and Engineering, vol. 35, no. 2, pp. 260-267, 2016.

[6] S. P. Li and D. X. Wu, "Effect of confining pressure, pore pressure and specimen dimension on permeability of yinzhuang sandstone," International Journal of Rock Mechanics and Mining Sciences, vol. 34, no. 4, pp. 435-441, 1997.

[7] X. J. Wang, G. Rong, and C. B. Zhou, "Premeability experimental study of gritstone in deformation and failure processes," Chinese Journal of Rock Mechanics and Engineering, vol. 31, no. S1, pp. 2940-2947, 2012.

[8] J. Yu, H. Li, X. Chen et al., "Triaxial experimental study of associated permeability-deformation of sandstone under hydro-mechanical coupling," Chinese Journal of Rock Mechanics and Engineering, vol. 32, no. 6, pp. 1203-1213, 2013.

[9] Y. Z. Zhang and H. G. Ji, "Pore water pressure change-related characteristic and its critical rupture precursor of rock under triaxial compression," Chinese Journal of Engineering, vol. 37, no. 4, pp. 399-406, 2015.

[10] H. L. Wang, W. Y. Xu, and S. Q. Yang, "Experimental investigation on permeability evolution law during course of deformation and failure of rock specimen," Rock and Soil Mechanics, vol. 27, no. 10, pp. 1703-1708, 2006.

[11] Z. D. Zhu and L. M. Li, "Experimental research on dynamic seepage characteristics of brittle rock," Journal of China Coal Society, vol. 28, no. 6, pp. 588-592, 2003.

[12] X. B. Li, X. Q. He, and H. J. Chen, "Crack initiation characteristics of opening-mode crack embedded in rock-like material under seepage pressure," Chinese Journal of Rock Mechanics and Engineering, vol. 31, no. 7, pp. 1317-1324, 2012.

[13] H. L. Wang and W. Y. Xu, "Permeability evolution laws and equations during the course of deformation and failure of brittle rock," Journal of Engineering Mechanics, vol. 139, no. 11, pp. 1621-1626, 2013.
[14] G. Siavash, S. Jean, G. Sylvine et al., "Effective stress law for the permeability of a limestone," International Journal of Rock Mechanics and Mining Sciences, vol. 46, no. 2, pp. 297-306, 2009.

[15] M. Jobmann, T. Wilsnack, and H.-D. Voigt, "Investigation of damage-induced permeability of opalinus clay," International Journal of Rock Mechanics and Mining Sciences, vol. 47, no. 2, pp. 279-285, 2010.

[16] R. Suzanne, V. Guy, C. Bernard et al., "Experimental study of the relation between the permeability of kaolinite and its deformation at micro and macro scale," International Journal of Rock Mechanics and Mining Sciences, vol. 47, pp. 559-567, 2010.

[17] T. Jiang, J. F. Shao, W. Y. Xu, and C. B. Zhou, "Experimental investigation and micromechanical analysis of damage and permeability variation in brittle rocks," International Journal of Rock Mechanics and Mining Sciences, vol. 47, no. 5, pp. 703-713, 2010.

[18] A. K. M. B. Alam, M. Niioka, Y. Fujii, D. Fukuda, and J.-I. Kodama, "Effects of confining pressure on the permeability of three rock types under compression," International Journal of Rock Mechanics and Mining Sciences, vol. 65, pp. 49-61, 2014.

[19] Y. Chen, S. Hu, K. Wei, R. Hu, C. Zhou, and L. Jing, "Experimental characterization and micromechanical modeling of damage-induced permeability variation in Beishan granite," International Journal of Rock Mechanics and Mining Sciences, vol. 71, pp. 64-76, 2014.

[20] P. Xu and S.-Q. Yang, "Permeability evolution of sandstone under short-term and long-term triaxial compression," International Journal of Rock Mechanics and Mining Sciences, vol. 85, pp. 152-164, 2016.

[21] L. N. Y. Wong, D. Li, and G. Liu, "Experimental studies on permeability of intact and singly jointed meta-sedimentary rocks under confining pressure," Rock Mechanics and Rock Engineering, vol. 46, no. 1, pp. 107-121, 2013.

[22] L. Zou, B. G. Tarasov, A. V. Dyskin, D. P. Adhikary, E. Pasternak, and W. Xu, "Physical modelling of stress-dependent permeability in fractured rocks," Rock Mechanics and Rock Engineering, vol. 46, no. 1, pp. 67-81, 2013.

[23] D. Ma, X. X. Miao, Z. Q. Chen, and X. B. Mao, "Experimental investigation of seepage properties of fractured rocks under different confining pressures," Rock Mechanics and Rock Engineering, vol. 46, no. 5, pp. 1135-1144, 2013.

[24] L. Liu, W. Y. Xu, H. L. Wang, W. Wang, and R. B. Wang, "Permeability evolution of granite gneiss during triaxial creep tests," Rock Mechanics and Rock Engineering, vol. 49, no. 9, pp. 3455-3462, 2016.

[25] B. Han, S. Y. Xie, and J. F. Shao, "Experimental investigation on mechanical behavior and permeability evolution of a porous limestone under compression," Rock Mechanics and Rock Engineering, vol. 49, no. 9, pp. 3425-3435, 2016.

[26] T. L. Xiao, X. P. Li, and S. P. Jia, "Triaxial test research and mechanical analysis based on structure surface effect of deep rock mass with single fissure," Chinese Journal of Rock Mechanics and Engineering, vol. 31, no. 8, pp. 1666-1673, 2012.

[27] T. L. Xiao, X. P. Li, and S. P. Jia, "Failure characteristics of rock with two pre-existing transfixion cracks under triaxial compression," Chinese Journal of Rock Mechanics and Engineering, vol. 34, no. 12, pp. 2455-2462, 2015.

[28] T. Xiao, M. Huang, C. Cheng, and Y. He, "Experimental investigation on the mechanical characteristics and deformation behaviour of fractured rock-like material with one single fissure under the conventional triaxial 
compressionfissure under the conventional triaxial compression," Shock and Vibration, vol. 2018, Article ID 2608639, 11 pages, 2018.

[29] T. Xiao, M. Huang, and M. Gao, "Experimental study of the mechanical characteristics of a rock-like material containing a preexisting fissure under loading and unloading triaxial compression," Advances in Civil Engineering, vol. 2020, Article ID 9374352, 12 pages, 2020. 